\title{
A Food Poisoning Outbreak Caused by Shigella in Al-Mafraq, Jordan, in 2019
}

\author{
Mais Alkhalili, MPH \\ Ministry of Health, Amman, Jordan

\section{Corresponding Author:} \\ Mais Alkhalili, MPH \\ Ministry of Health \\ Primary Health Care Directorate/ 6th Floor \\ Amman \\ Jordan \\ Phone: 962795509481 \\ Email: drmaiskhalili@gmail.com
}

\section{Abstract}

Background: On October 6, 2019, 55 residents of Bala'ama town in Al-Mafraq, Jordan, were admitted to the local health care center with symptoms of food poisoning.

Objective: This study aimed to identify the cause of the food poisoning outbreak.

Methods: This descriptive study is a cross-sectional study. Data were obtained from the Directorate of Communicable Diseases in the Ministry of Health. A total of 25 stool samples from patients and an additional 2 samples from workers in the restaurant were collected and tested. An environmental survey of the food and water was also conducted.

Results: The period of the outbreak was from October 6 to 10, 2019. The highest proportion of patients were children under 5 years of age. More females than males were affected. Stool test results were positive for Shigella sonnei in 15 samples and rotavirus in 7 samples. Chloride concentration was 0 in the water samples.

Conclusions: The food poisoning outbreak was caused by consumption of hummus from a neighborhood restaurant, which was contaminated with S. sonnei.

(iproc 2022;8(1):e36438) doi: $10.2196 / 36438$

\section{KEYWORDS}

food poisoning; outbreak; Shigella

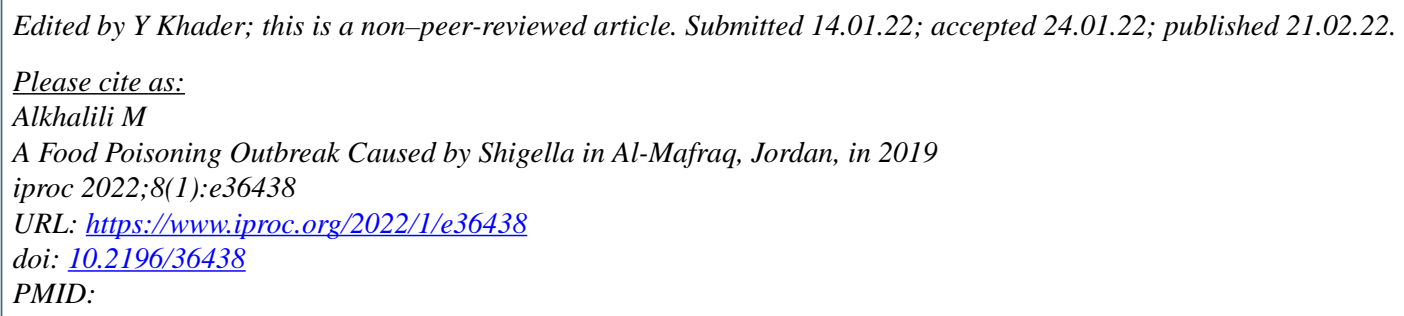

CMais Alkhalili. Originally published in Iproceedings (https://www.iproc.org), 21.02.2022. This is an open-access article distributed under the terms of the Creative Commons Attribution License (https://creativecommons.org/licenses/by/4.0/), which permits unrestricted use, distribution, and reproduction in any medium, provided the original work, first published in Iproceedings, is properly cited. The complete bibliographic information, a link to the original publication on https://www.iproc.org/, as well as this copyright and license information must be included. 